\title{
Pharmacological role and clinical applications of interleukin-6 in rheumatoid disease
}

This article was published in the following Dove Press journal:

International Journal of Interferon, Cytokine and Mediator Research

14 April 2010

Number of times this article has been viewed

\author{
Pierre Youinou ${ }^{1,2}$ \\ Sophie Hillion ${ }^{1,2}$ \\ Gabriel J Tobón ${ }^{1,2}$ \\ Divi Cornec ${ }^{1,2}$ \\ Jacques-Olivier Pers ${ }^{1,2}$ \\ Alain Saraux ${ }^{1,2}$ \\ Boutahar Bendaoud 1,2 \\ Yves Renaudineau ${ }^{1,2}$ \\ Christophe Jamin ${ }^{1,2}$ \\ 'Université Européenne de Bretagne \\ and Université de Brest, "Immunology \\ and Pathology", ${ }^{2} \mathrm{SclnBioS}$, Brest, \\ France; University Medical School \\ Hospital, Brest, France
}

Correspondence: Pierre Youinou Laboratory of Immunology, Brest University Medical School Hospital, BP 824, F 29609 Brest, France Email youinou@univ-brest.fr

\begin{abstract}
Interleukin (IL)-6 is a pleiotropic cytokine that promotes polyclonal activation of B lymphocytes. This implies that its deregulation favors inflammatory conditions. Through the association of the transducing glycoprotein 130 with the membrane-anchored receptor (R) $\alpha$, IL-6 can generate functionally distinct signals. Given these particular molecular aspects, numerous activities ascribed to this cytokine are, in fact, due to the insertion into soluble IL-6R $\alpha$. The system is instrumental in rheumatoid arthritis (RA), Sjögren's syndrome and systemic lupus erythematosus (SLE). In this respect, it is interesting that the expression of the recombination-activating gene is sustained by IL-6 in B lymphocytes, and repressed by anti-IL-6R antibody (Ab) in RA and SLE. Agents that inhibit IL-6 signaling have now entered clinical trials. As expected, clinical benefits are reported in the treatment of autoimmune disorders with anti-IL-6R Ab, but other perspectives remain open in the forthcoming biotherapies of immune-mediated disorders.

Keywords: interleukin-6, B lymphocyte, rheumatoid arthritis, systemic lupus erythematosus, Sjögren's syndrome, biotherapy
\end{abstract}

Over the past few years, a number of mediators have been reported as different factors, and characterized independently as potently active for inducing B cell growth and differentiation. These include the T cell replacing factor, the B cell stimulatory factor-2, the macrophage-derived survival agent, the myeloid differentiation proteins and the hepatocyte-stimulating cytokine. Progressively, the evidence went to prove that they duplicated each other, and the whole of them appeared to resemble interferon $-\mathrm{P} 2$ (IFN - $\beta 2$ ) so much, that it made sense to designate all these mediators as interleukin 6 (IL-6). Besides such amalgamation, the IL-6 set of cytokines encompasses, among others, the leukemia inhibitory factor (LIF), the ciliary neurotrophic factor, the IL-11, the cardiotrophin-1, and the cardiotrophin-like factors. ${ }^{1}$ Concomitant with such a bloom of ligands (Table 1), elucidation on the molecular mechanisms underlying this issue has yielded a first complementary DNA for the $80 \mathrm{kDa}$ IL- 6 binding $\alpha$ chain, and a second for the $130 \mathrm{kDa}$ IL-6 signal transducing $\beta$ chain. ${ }^{2,3}$ Two specimens of the former receptor chains (R) $\mathrm{R} \alpha$ associate with two of the latter glycoprotein gp 130 . Given that the resulting tetramer retains two molecules of IL-6, the plasma membrane is ultimately decorated with an hexamer. ${ }^{4}$

Once the complex of two IL-6 R $\alpha$ chains, two specimens of gp130 and two molecules of IL- 6 has been constructed, the cytokine included within the aggregate acquires the capacity to exert a variety of biological activities. The mechanisms operate in autocrine, paracrine and endocrine manners in wide-spread organs. The function of IL- 6 was originally considered to be confined to the promotion of

submit your manuscript | www.dovepress.con 
Table I The interleukin-6-type cytokine family

- Interleukin-6

- Leukemia inhibitory factor

- Ciliary neurotrophic factor

- Interleukin-II

- Cardiotrophin-I

- Cardiotrophin-like cytokine

immunoglobulin (Ig) release, but this has been extended to pro- and anti-inflammatory properties. Not only does it affect the immune system, but it orchestrates numerous other biological systems. Nevertheless, for B cells to proliferate and differentiate, IL-6 presents as an absolute requisite. ${ }^{5}$

This fundamental requirement shows this cytokine is central to the pathophysiology of B lymphocyte mediated systemic diseases. Uncontrolled overproduction of IL-6 appears to be responsible for the clinical symptoms and biological abnormalities of rheumatoid arthritis (RA), primary Sjögren's syndrome (pSS) and systemic lupus erythematosus (SLE). Insights have subsequently been gained into the relationship between IL-6, IL-17, and the IL-23 class of cytokines and the B cell activating factor of the tumor necrosis factor (TNF) family (BAFF) on the one side, and into the interdependence between $\mathrm{B}$ effector (Be) cell and T helper (Th) cell subset, on the other side. ${ }^{6-8}$ These stimulators of the synthesis of acute phase proteins by hepatocytes proceed from a number of cells, along with IL-1 $\beta$, IL-8, TNF $\alpha$, and transforming growth factor- $\beta$ (TGF $\beta$ ). Such discoveries have revolutionized our view about the pathophysiology of autoimmune diseases.

New technologies have brought a wealth of information about the role of respective $\mathrm{T}$ and $\mathrm{B}$ cell subsets throughout the inflammatory process. One consequence of this current revolution of biotherapies is that IL-6 is being converted into a grade one therapeutic target in the setting of immune mediated diseases. ${ }^{9}$ The rationale for its blockade consists of interfering with B cell functions, because B lymphocyte has recently moved to the center of the autoimmunity stage..$^{10}$ In this respect, various antagonists of IL-6R $\alpha$, most particularly antibodies (Abs), have shown considerable promise for the treatment of nonorgan-specific autoimmune disorders. ${ }^{11}$

\section{Immunopathology of interleukin-6 Production of interleukin-6}

IL-6 derives not only from immune cells, such as monocytes, macrophages, $\mathrm{T}$ and $\mathrm{B}$ lymphocytes, and polymorphonuclear cells (PMNs), but also from a variety of other cell types, such as fibroblasts, epidermal keratinocytes, adipocytes, hepatocytes, renal mesangial cells, and syncitiotrophoblasts. ${ }^{12}$ In addition, several tumor cell types generate IL-6, including plasmacytoma, multiple myeloma, and renal carcinoma cells. Among T lymphocytes, the synthesis of IL-6 is restricted to those polarized towards Th2, while, among B lymphocytes, it is restricted to those polarized towards Be2. ${ }^{13,14}$

\section{The cells impacted by interleukin- 6}

Proteases cleave the membrane anchored IL-6R $\alpha$, which is subsequently shed into the blood. The circulating cytokine binds to the IL-6R $\alpha$ membrane or to its cell-free form.

This association between the ligand and its receptor is not enough to launch the downstream cascade of immunological events. The soluble complex of IL- 6 and IL-6R $\alpha$ binds to the membrane gp130, but not to the membrane IL-6R $\alpha$. Indeed, the contribution of IL-6R $\beta$ is necessary to mediate signaling into cells (Figure 1). The IL-6R $\alpha$ is specific for hepatocytes, monocytes, PMNs, and T and B lymphocyte subsets, whereas the IL-6R $\beta$ is expressed by those cells and other body cells as well. ${ }^{15}$ Furthermore, the latter signal transducer is shared by LIF, IL-11, IL-12, IL-23, and so forth. The cascade is triggered off by this $\beta$ chain, once the cytokine has bound to its cognate $\alpha$ chain receptor, so the ensuing events are specific for this cytokine.

Complexes of IL-6 and IL-6R $\alpha$ fit into the IL-6R $\beta .{ }^{16}$ The process is unique, and the term "transsignaling" has been coined by Jones and colleagues to indicate this phenomenon. ${ }^{17}$ It raises the possibility that IL-6R $\alpha$ devoid cells become responsive to IL-6, even though activities to IL- 6 are mediated by soluble IL-6R $\alpha$, once the complexes have been retained by gp130. ${ }^{15}$ The model is supported by the conclusions of epitope mapping analyses that yield distinct sites. Alternatively, in the absence of IL-6, insoluble IL-6R $\alpha$ may be able to adhere to an hitherto unidentified receptor. Its endeavor covers local induction of intercellular adhesion molecules, production of supplemental proinflammatory cytokines, and recruitment of leukocytes to disease sites. ${ }^{18}$

In brief, as highlighted by Jones, IL- 6 has the capacity to orchestrate transition from innate inflammatory response to acquired immunity, as suggested but the early classification of IL-6 as a differentiation factor for T and B lymphocytes. ${ }^{19}$ Supporting this concept, poly (I-C), followed by muramyl dipeptide, up-regulates IL-6 and IL-8 in RA fibroblasts through activation of Toll-like receptors (TLR) TLR-2, TLR-3 and TLR-4 in culture. ${ }^{20}$ 




Figure I Interleukin (IL)-6 binds to soluble IL-6 receptor (R) $\alpha$ and this heterodimer inserts into the IL-6R $\beta$ on the membrane of all body cells.

\section{IL-6 signal transduction}

Once transduced downstream from the transmembrane receptor, the signal activates Janus tyrosine kinase (JAK) family members (Figure 2). There are four members of the JAK family, of which JAK1, JAK2 and tyk2 constitutively associate with gp 130. The sequence ends with the activation of signal transducer and activator (STAT) STAT1 and STAT3, and the translocation of these transcription factors from the cytoplasm to the nucleus. ${ }^{21}$ Other tyrosine residues of gp130 are recognized by the SH2containing protein tyrosine phosphatase 2 and the subsequent cascade of extracellular signal-regulated and mitogen activated protein kinases. Two suppressors of cytokine signaling (SOCS), SOCS1 and SOCS3, turn off the effects mediated by the IL-6 family of cytokines. ${ }^{22}$

\section{The cytokine network}

Generation of IL-17, producing Th17, despite its dependence on IL-23, requires only TGF $\beta$ plus IL-6, which is thus inserted into a cytokine network. ${ }^{23}$ The release of IL-17 by the Th17 $\mathrm{CD}^{+} \mathrm{T}$ lymphocytes is dependent on dendritic cell cytokines. ${ }^{6}$ Among these mediators, IL-23 is necessary for IL-6, and, given the absence of Th17 cells in IL-6-deficient mice, this second cytokine is not dispensable for evolvement of naïve $\mathrm{CD} 4^{+} \mathrm{T}$ lymphocytes into Th17 cells. ${ }^{24}$

\section{Is IL-6 relevant to autoimmunity? Rheumatoid arthritis}

The casual discovery of high levels of IL-6, associated with efflorescence of Abs in patients with cardiac myxoma was unexpected, and became the first clue as to whether IL- 6 might be central to autoimmunity. ${ }^{25}$ Investigators verified whether such was the case in conventional autoimmune diseases, and indeed the production of Il- 6 by RA activated synoviocytes was elevated, compared with that of synoviocytes of patients with osteoarthritis. High amounts of IL-6 were detected in synovial fluid from the joints of RA patients.

The mediator contributes to cartilage and bone destruction in RA, so that IL-6-deficient mice backcrossed to a susceptible genetic background resist collagen-induced arthritis (CIA) ${ }^{26}$

\section{Primary Sjögren's syndrome}

Whereas, the IL-6 levels in circulation stays low under normal conditions, its synthesis is up-regulated in patients 


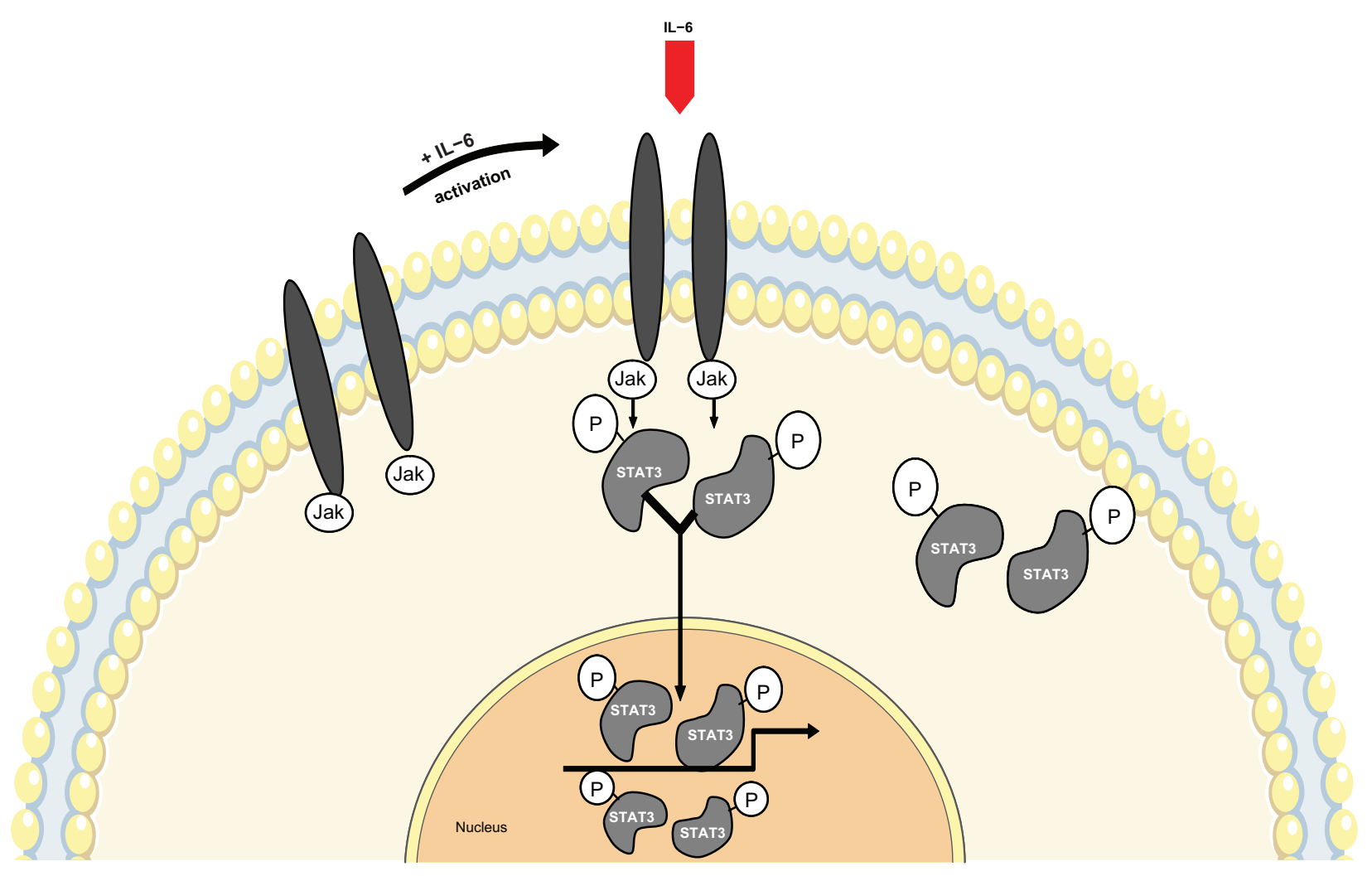

Figure 2 The JAK and STATI/STAT3 pathway, downstream from IL-6 of the plasma membrane IL-6 complex to the nucleus.

with pSS. Consequently, serum and saliva levels of IL-6 are elevated, messenger RNAs for IL-6 become detectable in their salivary glands, and the frequency of IL- 6 secreting cells is markedly increased in their peripheral blood. ${ }^{27,28}$

Locally, too much IL-6 is released by epithelial cells of the glands, and an increased proportion of infiltrating lymphocytes produce IL-6 in pSS. Consistent with this view, inflammation has been implicated in polyclonal B cell activation and monoclonal $\mathrm{B}$ cell neoplasia in these patients. A handful of cytokines have been found to differ between patients and controls. ${ }^{29}$ These include IL-1 $\beta$, IL-6, IL-8, IL-12, TNF- $\alpha$ and BAFF. 30

\section{Systemic lupus erythematosus}

Similarly, B cells from patients with SLE express spontaneously high levels of IL-6, and harbor receptors for IL- $6 .{ }^{30}$ These findings suggest that the scenario is autocrine, and that part of the B cell hyperactivity is independent of $\mathrm{T}$ cell assistance. Some researchers claim that urinary IL-6 denotes lupus proliferative glomerulonephritis. ${ }^{31}$ This may be ascribed to infiltrating inflammatory cells, as the major source of IL-6 in the kidney of patients with lupus nephritis. ${ }^{32}$

Early data found IL- 6 to be a strong inducer of $\mathrm{B}$ cell differentiation into IgG-secreting plasma cells. In the context of SLE, later studies established that, apart from IL-6, no other cytokine is capable of directly triggering the anti-double-stranded (ds) DNA Ab production. ${ }^{33}$ Conversely, incubation of SLE B cells with anti-IL-6 and/or anti-IL-6R Abs reduces total IgG production, as well as that of anti-dsDNA Ab, in a dose dependent manner. ${ }^{34}$

\section{Miscellaneous}

Overproduction of IL-6 has then been described in a number of autoimmune settings (myasthenia gravis, multiple sclerosis, systemic-onset juvenile idiopathic arthritis, and insulin dependent diabetes mellitus), a variety of inflammatory conditions (asthma, septic shock, stress, and inflammatory bowel diseases), and a handful of neoplastic disorders (colon cancer, multiple myeloma, head and neck squamous cell carcinoma, and B cell malignancies). ${ }^{35,36}$

Plasma IL-6 levels increase with advancing age, due to age-associated diseases, and to the fact that sex hormones, known to repress IL-6 expression, diminish with age.

\section{IL-6-targeted treatments}

\section{The basic mechanisms}

The ability of IL-6 to induce the maturation and differentiation of the cells is consistent with some form of epigenetic 
control over the differentiation process. The most efficient way to silence a gene is to transfer methyl groups to cytosine-phosphate-guanosine motifs in their promoter by the DNA methyltransferase (DNMT) family, where DNMT1 is a maintenance methylase. ${ }^{37}$ In the absence of changes in total cyclin or cyclin E-dependent kinase expression in SLE, the abnormalities should rely on IL-6 mediated cell cycle arrest at the G0/G1 interface. Thus, IL-6-induced cell cycle arrest blocks the action of DNMTs and thereby renders any methylation induced repression of the IL- 6 gene impossible. ${ }^{38}$ IL-6 protein in excess transactivates the expression of the DNMT1 promoter by regulating transcription of the Friend leukemia virus integration protein, FLI-1, which is one of its transcription factors. ${ }^{39}$

\section{Perspectives in biotherapy}

As that of other cytokines, the paradigm of IL- 6 has recently been shifted from basic science to therapeutic medicine, and valuable strategies have been recently launched for inflammatory diseases (Table 2). Although anti-IL-6 seems most appropriate as a target for therapy, accumulation of IL-6 in the form of monomeric immune complexes has been observed, following injection of the $\mathrm{mAb}$ against the cytokine into the animals. ${ }^{40,41}$

Hence, it stands to reason that to substitute anti-IL6 mAb with anti-IL-6R mAb that blocks the transmembrane, as well as the soluble forms of IL-6R, is the most logical strategy to be efficient. ${ }^{42}$ Clinical benefits have recently been obtained in RA. The Study of Active Monotherapy used for RA IL-6 inhibitor (referred to as the "SAMURAI trial"), has shown

Table 2 Perspectives in therapy with anti-interleukin (IL)-6 or anti-IL-6 receptor antibody

- Autoimmune diseases
- Rheumatoid arthritis
- Primary Sjögren's syndrome
- Systemic lupus erythematosus
- Hashimoto thyroiditis (unpublished)
- Systemic-onset juvenile idiopathic arthritis
- Myasthenia gravis
Other inflammatory conditions
- Castleman's disease
- Crohn's disease
- Asthma
Other disease states
- Septic shock
- Multiple myeloma
- B cell malignancies

limitation of radiographic progression, as compared with conventional disease modifying anti-rheumatic drugs. ${ }^{43}$ Furthermore, rapid and sustained improvement in bone and cartilage turnover markers with tocilizumab (TZM) plus methotrexate has been observed in RA patients with an adequate response to methotrexate. ${ }^{44} \mathrm{TZM}$ is a humanized anti-human IL-6R Ab recently developed in Japan. This $\mathrm{mAb}$ binds to the $\alpha$ chain of the membrane-bound and cellfree receptor. Although its safety profile has not been fully defined, this agent has been shown to prevent structural joint damages. It induced rapid, marked, and dose dependent reductions in the levels of biochemical markers of cartilage which are N-terminal propeptide of type IIA, collagen helical peptide and matrix metalloproteinase 3, providing evidence of a beneficial effect on bone turnover. Parallel trials may help the decision making process, but Maini and the CHARISM A study group, for the Chugai humanized anti-human recombinant IL-6 $\mathrm{mAb}$ have also reported on the efficacy of TZM in 359 patients with RA. ${ }^{45}$

Similar success has been obtained in systemic-onset juvenile idiopathic arthritis, Castleman's disease (a similar condition to pSS), and Crohn's disease (a chronic inflammatory bowel disease of unknown etiology). ${ }^{46-48}$ No differences have been shown in the incidence of adverse events between the patients who received placebo and those who received TZM. ${ }^{49}$

One may also envision IL-6-related trials in other inflammatory disorders, including ankylosing spondylitis and psoriasis. Still to be established, are whether transition from acute to chronic inflammation occurs in relation with a breakdown in the IL-6 control, and to decipher the interplay of endothelial growth factor $\beta$ and other cytokines with IL-6.

\section{Conclusion}

Progress in the study of IL-6 has generated innovative concepts. ${ }^{13}$ IL- 6 is indeed a particular case of signal transduction and serves as the signal orchestration model. Recent advances have been made in mapping the immunopathophysiology of this cytokine, so are we likely to learn about autoimmune diseases, and IL-6-regulated tumors where targets for anti-IL-6 R therapy might also be expanded. ${ }^{26,50}$ Furthermore, the antagonists for IL-6 might be associated with those for BAFF.

One area of consideration is the question of whether TZM has a better risk-benefit balance than established mAbs. However, some investigators believe that this agent could well become a first-line therapy in RA and related systemic autoimmune diseases. 


\section{Acknowledgments}

Thanks are due to Simone Forest and Geneviève Michel for their help with the typing of the manuscript and to the artist, Simone Forest, for assistance.

\section{Disclosures}

The authors report no conflicts of interest in this work.

\section{References}

1. Youinou P, Jamin C. The weight of interleukin-6 in B cell-related autoimmune disorders. J Autoimmun. 2009;32:206-210.

2. Yamasaki K, Taga T, Hirata Y, Yawata H, Kawanishi Y, Seed B, et al. Cloning and expression of the human IL-6 receptor. Science. 1988;241: $825-828$.

3. Hibi M, Murakami M, Saito M, Hirano T, Taga T, Kishimoto T. Molecular cloning and expression of an IL-6 signal transducer, gp130. Cell. 1990;63:1149-1157.

4. Ward LD, Howlett GJ, Discolo G, Yasukawa K, Hammacher A, Moritz RL, et al. High affinity IL-6 receptor is a hexameric complex consisting of two molecules each of IL-6, IL-6 receptor, and gp-130. J Biol Chem. 1994;269:23286-23289.

5. Jelinek DF, Lipsky PE. Regulation of human B lymphocyte activation, proliferation, and differentiation. Adv Immunol. 1987;40:1-59.

6. Acosta-Rodriguez EV, Napolitani G, Lanzavecchia A, Sallusto F. IL-1 $\beta$ and 6 but not TGF-B are essential for the differentiation of IL-17-producing human T helper cells. Nat Immunol. 2007;8:942-949.

7. Doreau A, Belot A, Bastid J, et al. Interleukin 17 acts in synergy with $B$ cell-activating factor to influence $B$ cell biology and the pathophysiology of systemic lupus erythematosus. Nat Immunol. 2009;10:778-785.

8. Daridon C, Guerrier T, Devauchelle V, Saraux A, Pers JO, Youinou P. Polarization of B effector cells in Sjögren's syndrome. Autoimmun Rev. 2007;6:427-431.

9. Nishimoto N, Kishimoto T, Yoshizaki K. Anticytokine therapy in autoimmune diseases. Intern Med. 1999;38:178-182.

10. Youinou P. B cells conduct the lymphocyte orchestra. J Autoimmune. 2007;28:143-151.

11. Connell L, McInnes IB. New cytokine targets in inflammatory rheumatic diseases. Best Pract Res Clin Rheumatol. 2006;20:865-878.

12. Kamimura D, Ishihara K, Hirano T. IL-6 signal transduction and its physiological roles: the signal orchestration model. Rev Physiol Biochem Pharmacol. 2003;149:1-38.

13. Romagnani S. Regulation of the T cell response. Clin Exp Allergy. 2006;36:1357-1366.

14. Amel Kashipaz MR, Huggins ML, Lanyon P, Robins A, Powell RJ, Todd I. Assessment of $\mathrm{Be} 1$ and $\mathrm{Be} 2$ cells in SLE indicates elevated il-10 producing CD5+ B cells. Lupus. 2003;12:356-363.

15. Scheller J, Rose-John S. IL-6 and its receptor: from bench to bedside. Med Microbiol Immunol. 2006;195:173-183.

16. Knüpfer H, Preiss R. sIL-6R: more than an agonist? Immunol Cell Biol. 2008;86:87-91.

17. Jones SA, Richards PJ, Scheller J, Rose-John S. IL-6 transsignaling: the in vivo consequences. J Interferon Cytokine Res. 2005;25:241-253.

18. Akira S, Hirano T, Taga T, Kishimoto T. Biology of multifunctional cytokines: IL-6 and related molecules. FASEB J. 1990;4:2860-2867.

19. Jones SA. Directing transition from innate to acquired immunity: defining a role for IL-6. J Immunol. 2005;175:3463-3468.

20. Ospelt C, Brentano F, Jüngel A, Rengel Y, Kolling C, Michel BA, et al. Expression, regulation, and signaling of the pattern-recognition receptor nucleotide-binding oligomerization domain 2 in rheumatoid arthritis synovial fibroblasts. Arthritis Rheum. 2009;60:355-363.

21. Heinrich PC, Behrmann I, Haan S, Hermanns HM, Müller-Newen G, Schaper F. Principles of IL-6-type cytokine signalling and its regulation. Biochem J. 2003;374:1-20.
22. Croker BA, Kiu H, Nicholson SE. SOCS regulation of the JAK/STAT signalling pathway. Semin Cell Dev Biol. 2008;19:414-422.

23. Acosta-Rodriguez EV, Napolitani G, Lanzavecchia A, Sallusto F. Interleukins 1 beta and 6 but not transforming growth factor-beta are essential for the differentiation of interleukin 17-producing human $\mathrm{T}$ helper cells. Nat Immunol. 2007;8:942-949.

24. Ivanov II, McKenzie BS, Zhou L, Tadokoro CE, Lepelley A, Lafaille JJ, et al. The orphan nuclear receptor RORgammat directs the differentiation program of proinflammatory IL-17+T helper cells. Cell. 2006;126:1121-1133.

25. Jourdan M, Bataille R, Seguin J, Zhang XG, Chaptal PA, Klein B. Constitutive production of IL-6 and immunologic features in cardiac myxomas. Arthritis Rheum. 1990;33:398-402.

26. Ohshima S, Saeki Y, Mima T, Sasai M, Nishioka K, Nomura S, et al. IL-6 plays a key role in the development of antigen-induced arthritis. Proc Natl Acad Sci U SA. 1998;95:8222-8226.

27. Fox RI, Kang HI, Ando D, Abrams J, Pisa E. Cytokine mRNA expression in salivary gland biopsies of Sjögren's syndrome. J Immunol. 1994;152:5532-5539.

28. Halse A, Tengnér P, Wahren-Herlenius M, Haga H, Jonsson R. Increased frequency of cells secreting IL- 6 and IL-10 in peripheral blood of patients with primary Sjögren's syndrome. Scand J Immunol. 1999;49:533-538.

29. Szodoray P, Alex P, Brun JG, Centola M, Jonsson R. Circulating cytokines in primary Sjögren's syndrome determined by a multiplex cytokine array system. Scand J Immunol. 2004;59:592-599.

30. Nagafuchi H, Suzuki N, Mizushima Y, Sakane T. Constitutive expression of IL-6 receptors and their role in the excessive B cell function in patients with SLE. J Immunol. 1993;151:6525-6534.

31. Gordon C, Richards N, Howie AJ, Richardson K, Michael J, Adu D, et al. Urinary IL-6: a marker for mesangial proliferative glomerulonephritis? Clin Exp Immunol. 1991;86:145-149.

32. Takemura T, Yoshioka K, Murakami K, Akano N, Okada M, Aya N, et al. Cellular localization of inflammatory cytokines in human GNA. Virchows Arch. 1994;424:459-464.

33. Richards HB, Satoh M, Shaw M, Libert C, Poli V, Reeves WH. IL-6 dependence of anti-DNA antibody: evidence for two pathways of autoantibody formation in pristane-induced lupus. $J$ Exp Med. 1998;188:985-990.

34. Nishimoto N, Kishimoto T. Interleukin 6: from bench to bedside. Nat Clin Pract Rheumatol. 2006;2:619-626.

35. Ishihara K, Hirano T. IL-6 in autoimmune disease and chronic inflammatory proliferative disease. Cytokine Growth Factor Rev. 2002;13:357-368.

36. Scheller J, Ohnesorge N, Rose-John S. IL-6 transsignaling in chronic inflammation and cancer. Scand J Immunol. 2006;63:321-329.

37. Hodge DR, Xiao W, Clausen PA, Heidecker G, Szyf M, Farrar WL. IL-6 regulation of the human DNA methyltransferase gene in human erythroleukemia cells. J Biol Chem. 2001;276:39508-39511.

38. Nakase H, Takahama Y, Akamatsu Y. Effect of CpG methylation on RAG1/RAG2 reactivity: implications of direct and indirect mechanisms for controlling V(D)J cleavage. EMBO Rep. 2003;4:774-780.

39. Wendling $\mathrm{D}$, Racadot $\mathrm{E}$, Wijdenes J. Treatment of severe rheumatoid arthritis by anti-IL-6 monoclonal antibody. J Rheumatol. 1993;20:259-262.

40. Mihara M, Nishimoto N, Yoshizaki K, Suzuki T. Influences of anti-IL-6 receptor antibody on immune responses in mice. Immunol Lett. 2002;84:223-229.

41. Choy EH, Isenberg DA, Garrood T, et al. Therapeutic benefit of blocking IL-6 activity with an anti-IL-6 receptor monoclonal antibody in rheumatoid arthritis: a randomized, double-blind, placebo-controlled, dose-escalation trial. Arthritis Rheum. 2002;46:3143-3150.

42. Jostock T, Müllberg J, Ozbek S, et al. Soluble gp130 is the natural inhibitor of soluble IL-6 receptor transsignaling responses. Eur J Biochem. 2001;268:160-167.

43. Nishimoto N, Hashimoto J, Miyasaka N, et al. Study of active controlled monotherapy used for rheumatoid arthritis, an IL-6 inhibitor (SAMURAI): evidence of clinical and radiographic benefit from an $\mathrm{x}$ ray reader-blinded randomised controlled trial of tocilizumab. Ann Rheum Dis. 2007;66:1162-1167. 
44. Garnero P, Thompson E, Woodworth T, Smolen JS. Rapid and sustained improvement in bone and cartilage turnover markers with the anti-IL6 receptor inhibitor tocilizumab plus methotrexate in rheumatoid arthritis patients with an inadequate response to methotrexate. Results from a substudy of the multicenter double-blind, placebo-controlled trial of tocilizumab in inadequate responders to methotrexate alone. Arthritis Rheum. 2009;62:33-43.

45. Maini RN, Taylor PC, Szechinski J, et al. Double-blind randomized controlled clinical trial of the interleukin- 6 receptor antagonist, tocilizumab, in European patients with rheumatoid arthritis who had an incomplete response to methotrexate. Arthritis Rheum. 2006;54: 2817-2829.

46. Yokota S, Miyamae T, Imagawa T, et al. Therapeutic efficacy of humanized recombinant anti-IL-6 receptor antibody in children with systemic-onset juvenile idiopathic arthritis. Arthritis Rheum. 2005;52:818-825.
47. Nishimoto N, Kanakura Y, Aozasa K, et al. Humanized anti-IL-6 receptor antibody treatment of multicentric Castleman's disease. Blood. 2005;106:2627-2632.

48. Ito H, Takazoe M, Fukuda Y, et al. A pilot randomized trial of a human anti-interleukin-6 receptor monoclonal antibody in active Crohn's disease. Gastroenterology. 2004;126:989-996; discussion 947.

49. Nishimoto N, Yoshizaki K, Miyasaka N, et al. Treatment of rheumatoid arthritis with humanized anti-interleukin-6 receptor antibody: a multicenter, double-blind, placebo-controlled trial. Arthritis Rheum 2004;50:1761-1769.

50. Scheller J, Ohnesorge N, Rose-John S. Interleukin-6 trans-signalling in chronic inflammation and cancer. Scand J Immunol. 2006;63: 321-329.

International Journal of Interferon, Cytokine and Mediator Research

\section{Publish your work in this journal}

The International Journal of Interferon, Cytokine and Mediator Research is an international, peer-reviewed, open-access, online journal. The focus of the journal is to publish original research, reports, editorials, reviews and commentaries on all aspects of interferon, cytokine and mediators of inflammation from labora- tory science to therapeutic indications and clinical studies. The manuscript management system is completely online and includes a very quick and fair peer-review system, which is all easy to use. Visit http://www.dovepress.com/testimonials.php to read real quotes from published authors.

Submit your manuscript here: http://www.dovepress.com/international-journal-of-interferon-cytokine-and-mediator-research-journal 